\title{
JOINT PROGRAM FOR AUTOMATIC ANALYSIS OF ASTROGRAPHIC PLATES
}

\author{
A.LOPEZ GARCIA, J.L.VALDES NAVARRO, A.ORTIZ GIL AND \\ J.M.MARTINEZ GONZALEZ \\ Valencia University Observatory \\ 46010, Valencia, Spain \\ e-mail: obsast@vm.ci.uv.es \\ AND \\ V.N.YERSHOV, E.V.POLIAKOV, H.I.POTTER AND L.YAGUDIN \\ Pulkovo Observatory \\ 196140 Saint Petersburg, Russia \\ e-mail: yersh@gao.spb.su
}

Pulkovo and Valencia observatories are developing measuring machines based on the "Ascorecord" microscope that allow to undertake automatic measuring programs of different kind of plates (Ortiz et al., 1993). All aspects of astrometry work are covered now by our software: field maps and plate files creation from the PPM and the GSC; precise ephemeris calculation of minor planets and comets, including planetary perturbations; image identification and automatic plate measurement and reduction (Lopez et al., 1994a). For these tasks, correction tables for GSC catalogue vs. PPM, systematic errors (Lopez et al., 1994b) have been obtained. Observing programs using plates and CCD devices at telescope focus are planned (the search of new asteroids and comets, big planets satellites observation, new high density photographic catalogues and some other projects).

\section{References}

Lopez Garcia, A., Ortiz Gil, A., Martinez Gonzalez, J.M. and Poliakov, E. (1994a), Newsletter, No. 5. IAU WG on Wide-Field Imaging. (1994) UK.

Lopez, G.A., Martinez, G.J.M., Ortiz, G.A. and Yagudin, L.I. (1994b), Newsletter, N. 6. IAU WG on Wide-Field Imaging. (1994). UK. (In press).

Ortiz, G.A., Lopez, G.A., Martinez G.J.M. and Yershov, V. (1993) Automatic measurement of images in astrometric plates, Proc. IAU Symp.160,, UK (in press). 